\title{
Microscopic strain localisation in WAAM Ti-6Al-4V during uniaxial tensile loading
}

\author{
David Lunt ${ }^{1}{ }^{*}$, Alistair Ho ${ }^{1}$, Alec Davis ${ }^{1}$, Filomeno Martina ${ }^{2}$, Jan Hönnige ${ }^{2}$, João Quinta da Fonseca ${ }^{1}$, Phillip Prangnell ${ }^{1}$ \\ ${ }^{1}$ University of Manchester, Oxford Road, Manchester, M13 9PL, \\ ${ }^{2}$ Welding Engineering and Laser Processing Centre, Cranfield University, Bedfordshire, MK43 0AL, UK
}

*David.lunt@manchester.ac.uk

\section{$\underline{\text { Abstract }}$}

Wire Arc-Based Additive manufacturing is a high deposition rate process suitable for building large-scale aerospace components. However, the larger heat source can cause greater microstructural heterogeneity and, in particular, a coarse columnar $\beta$ grain structure. The effect of the subsequent related transformation microstructure heterogeneity on the mechanical behaviour is investigated, in both standard WAAM materials and samples subjected to inter-pass rolling, which leads to substantial $\beta$ grain refinement and texture randomisation. Full-field strain maps were produced by digital image correlation, using tensile samples loaded in different orientations. When loaded normal to the columnar grain structure, it is shown that the coarse $\beta$ grains lead to a highly heterogeneous deformation distribution, which is linked the presence of dominant hard and soft $\alpha$ variants in texture colonies within each parent $\beta$ grain. $\beta$ grain refinement through the application of inter-pass rolling was found to be very effective at homogenising the strain localisation for all test orientations.

\section{Introduction}

Additive Manufacturing (AM) is increasingly enabling the production of near-net shape components, with shorter lead times and greater design flexibility [1-3]. Wire-Arc Additive Manufacturing (WAAM) has the advantage of achieving the high deposition rates ( $>4 \mathrm{~kg}$ /hour) required to economically produce large-scale structural components [4]. However, $\mathrm{AM}$ with Ti-6Al-4V gives rise to microstructural heterogeneity not seen in wrought products [5] and, most significantly, to the formation of coarse columnar $\beta$ grain structures with a strong $\langle 001\rangle_{\mathrm{BCC}}$ fibre solidification texture [6-14]. Furthermore, the multiple thermal cycles in AM can lead to systematic additional microstructural variation, such as HAZ banding [11,15-19].

The formation of such heterogeneous microstructures is expected to contribute to unpredictability in the mechanical performance of AM components. For example, significant anisotropy has been observed [20]due to the large columnar $\beta$-grain structure and its associated $\alpha$ transformation texture [21,22]. Effective refinement of the $\beta$ grains can be achieved in WAAM through the introduction of an inter-pass rolling [23]. In contrast to conventional deposits, where the columnar $\beta$ grains can be several centimetres in length, inter-pass rolling can produce an equiaxed $\beta$ grain size of less than $100 \mu \mathrm{m}$ with weak texture [24], which leads to an improvement in mechanical properties [24](Fig. 1) including an increase in strength and a significant reduction in both the scatter and anisotropy in tensile performance. While this improvement has been linked qualitatively to the influence of heterogeneity in the local texture inherited from the parent $\beta$-grains [17], and the concentration of failure in the grain boundary $\alpha$ regions, the strain distribution in such materials has not been previously quantitatively correlated to their microtexture.

Digital Image Correlation (DIC) is a robust experimental method that enables full-field strain measurements to be made on the surface of a material at multiple length scales [25] and has been successful in observing differences in strain localisation in Ti-6Al-4V wrought products [26]. Previous work on AM Ti-6Al-4V has also indicated that different microtextures and $\alpha$ lath orientations associated with the parent $\beta$ grain boundaries can play an important role in strain localisation [27]. However, the high resolution used in this study meant that only a few grains were observed and the overall macroscale heterogeneity was not captured.

The overall aim here was therefore to use DIC to further investigate strain localisation in WAAM samples and determine whether the introduction of inter-pass rolling helped to homogenise the strain distribution. By capturing the entire gauge length, the full macroscopic deformation behaviour could be observed, enabling critical regions of localisation to be identified and compared to the underlying transformation microstructure and local microtexture, obtained from EBSD grain orientation mapping.
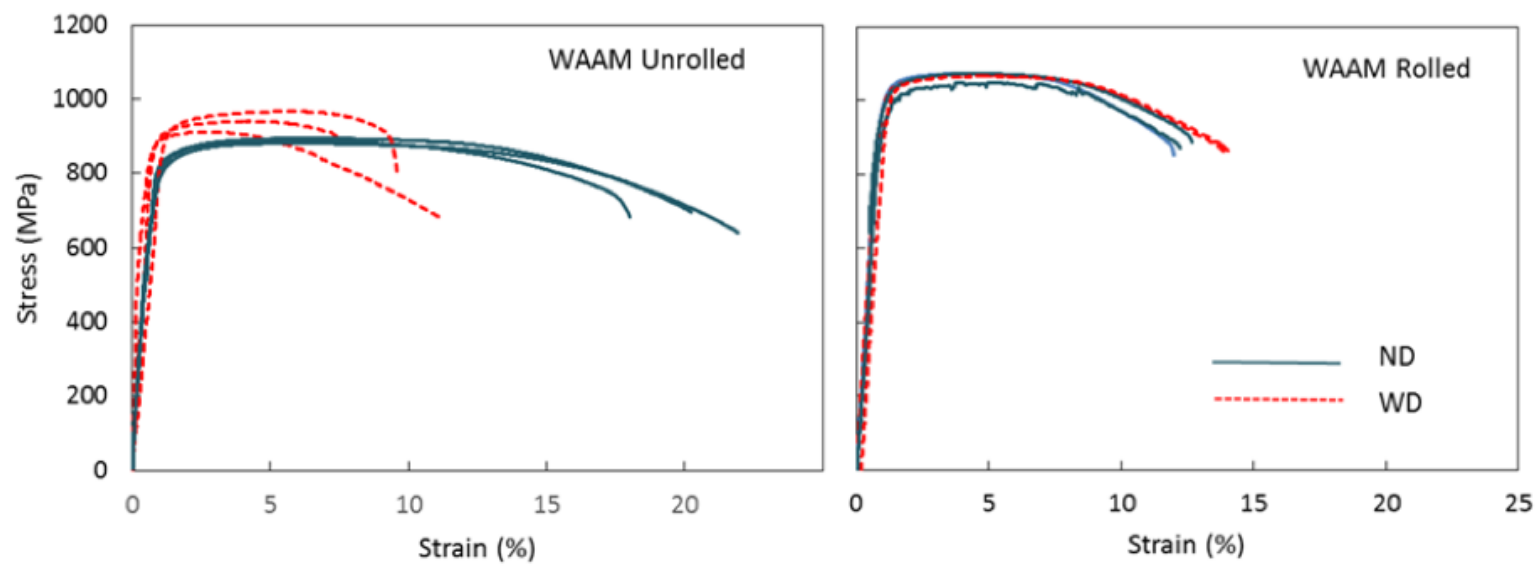

Figure 1- Stress-strain curves for unrolled and rolled WAAM Ti-6AI-4V tested in parallel and perpendicular to the build direction. Data provided by Cranfield University.

Table 1- WAAM-PAW deposition parameters

\begin{tabular}{ll}
\hline Wire Feed Speed & $2.4 \mathrm{~m} \mathrm{~min}^{-1}$ \\
Travel Speed & $7 \mathrm{~mm} \mathrm{~s}^{-1}$ \\
1st 6 Layers Current & $165 \mathrm{~A}$ \\
Current after 6 layers & $150 \mathrm{~A}$ \\
Plasma Gas & $1 \mathrm{~L} \mathrm{~min}-1$ \\
Local Shielding Gas (Argon) & $10 \mathrm{~L} \mathrm{~min}-1$ \\
Trailing Shielding Gas & $25 \mathrm{~L} \mathrm{~min}-1$ \\
Work Piece Distance/Torch stand off & $8 \mathrm{~mm}$ \\
Rolling Load & $66 \mathrm{kN}$ \\
Rolling Diameter Roller & $100 \mathrm{~mm}$ \\
Wire Type & Ti64 ERTi-5 \\
Wire Specification & $1.2 \mathrm{~mm} *$ D300 \\
\hline
\end{tabular}

(C) The Authors, published by EDP Sciences. This is an open access article distributed under the terms of the Creative Commons Attribution License 4.0 (http://creativecommons.org/licenses/by/4.0/). 


\section{Experimental Procedure}

WAAM Samples

Single pass wide walls ( $250 \mathrm{~mm}$ long, $55 \mathrm{~mm}$ high and $1.1 \mathrm{~mm}$ thick) was produced by plasma wire deposition (PWD) at Cranfield University Welding Engineering Research Centre UK using the parameters in Table 1 [24]. The sample reference frame is defined as; the heat source travel direction parallel to each layer (or 'welding' direction) (WD), transverse direction (TD) and the build height direction normal to each layer (ND). Specimens were extracted for tensile testing using electric discharge machining (EDM) from unrolled, rolled and 'abnormally' (containing some isolated unrolled layers) rolled builds. The rolled samples were produced with a load of $66 \mathrm{kN}$. The tensile specimens had a 26 by $3 \mathrm{~mm}^{2}, 1 \mathrm{~mm}$ thick, gauge length and were finish polished with colloidal silica (OP-S) mixed with $5 \%$ hydrogen peroxide, followed by etching in Kroll's solution for 3 minutes, to provide a distinct pattern for DIC.

Digital Image Correlation and Mechanical Loading

Ex-situ incremental DIC tensile loading experiments were performed using a Deben $5 \mathrm{kN}$ microtester, at a displacement rate of $0.02 \mathrm{~mm} / \mathrm{min}$. After each deformation step the samples were removed and imaged using a Zeiss Axio optical microscope, equipped with mapping software, to obtain a matrix of 4 by 36 stitched images along the gauge length, with a spatial resolution of $0.547 \mu \mathrm{m} /$ pixel (Fig. 2). Re-loading and subsequent image mapping were repeated up to a strain of $\sim 3-5 \%$. In each step the edges of the samples were carefully re-aligned to minimise any rotation artefacts. The stitched images were processed using LaVision's DIC software DaVis 8.4 . The image correlation calculation was carried out using and adaptive fast Fourier transform (FFT) algorithm, with a final interrogation window size of $32 \times 32$ pixels ${ }^{2}$ and no overlap equating to a spatial resolution of $17.51 \mu \mathrm{m}$.

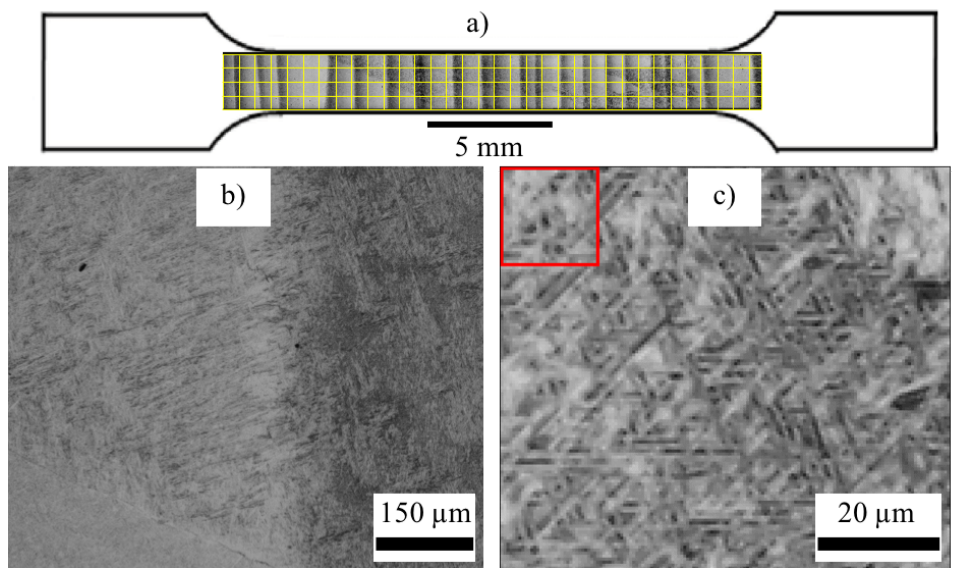

Figure 2- a) Example of the image acquisition process across the entire gauge length of the specimen, b) Image of a region taken from a single tile, c) Example of the pattern resolution captured by the optical microscope with an interrogation window size of $32 \times 32$ pixels given by the red box.

Grain Orientation Mapping

Post deformation, the samples were lightly re-polished in colloidal silica to remove the etch pattern and allow electron back scatter diffraction (EBSD) analysis of regions of interest, using an FEI Sirion scanning electron microscope (SEM) equipped with an AZtec EBSD system and a Nordlys II detector, at an accelerating voltage of $20 \mathrm{kV}$. The EBSD maps were analysed with HKL Channel $5^{\mathrm{TM}}$ software and correlated with regions of interest highlighted in the DIC strain maps. $\beta$ reconstruction software, developed by Davies et al. [28], was used to determine the parent $\beta$ grain structure from the room temperature $\alpha$ orientations.

\section{$\underline{\text { Results }}$}

Microstructures

Fig. 3 shows $\alpha$ and reconstructed $\beta$ orientation maps from typical regions along the gauge lengths for the different WAAM samples investigated. The standard unrolled sample contains few $\beta$-grains across the image width (Fig. 3a). In comparison, the rolled condition (Fig. 3b) exhibits a fine uniform $B$ grain size of $150-200 \mu$ m. Finally, the 'abnormal' rolled sample (Fig. 3c) shows large variation in $\beta$ grain size across its gauge length, with several large grains of up to $800 \mu \mathrm{m}$ and neighbouring grains as small as $100 \mu \mathrm{m}$. 
$\alpha$
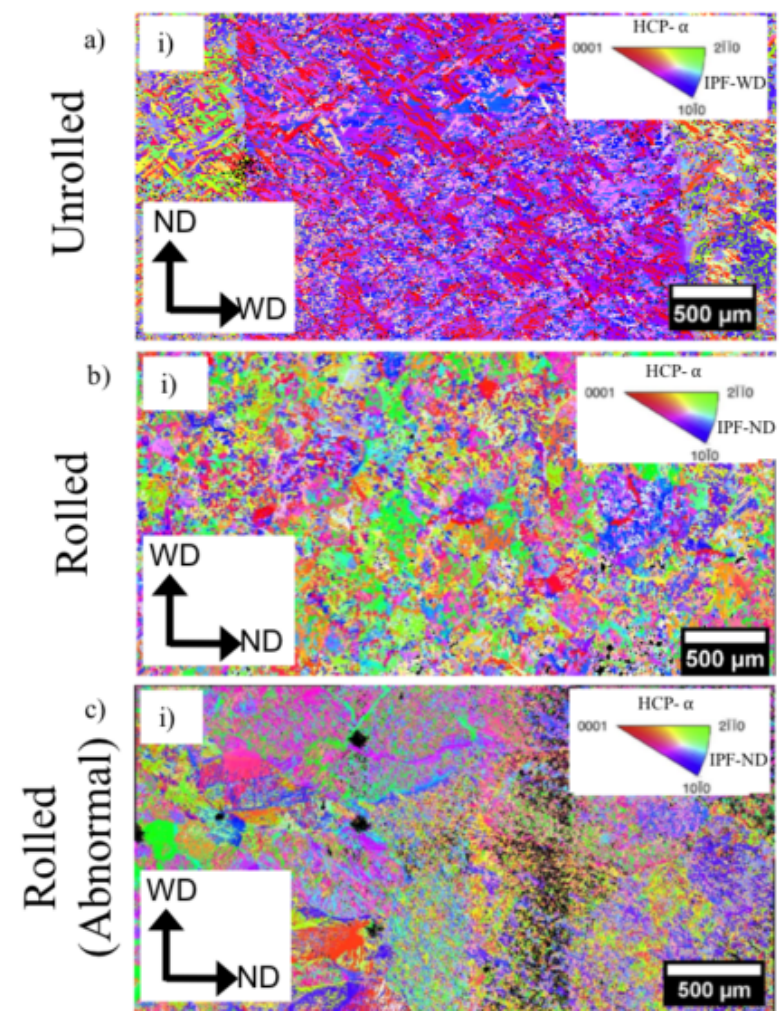

Reconstructed $\beta$
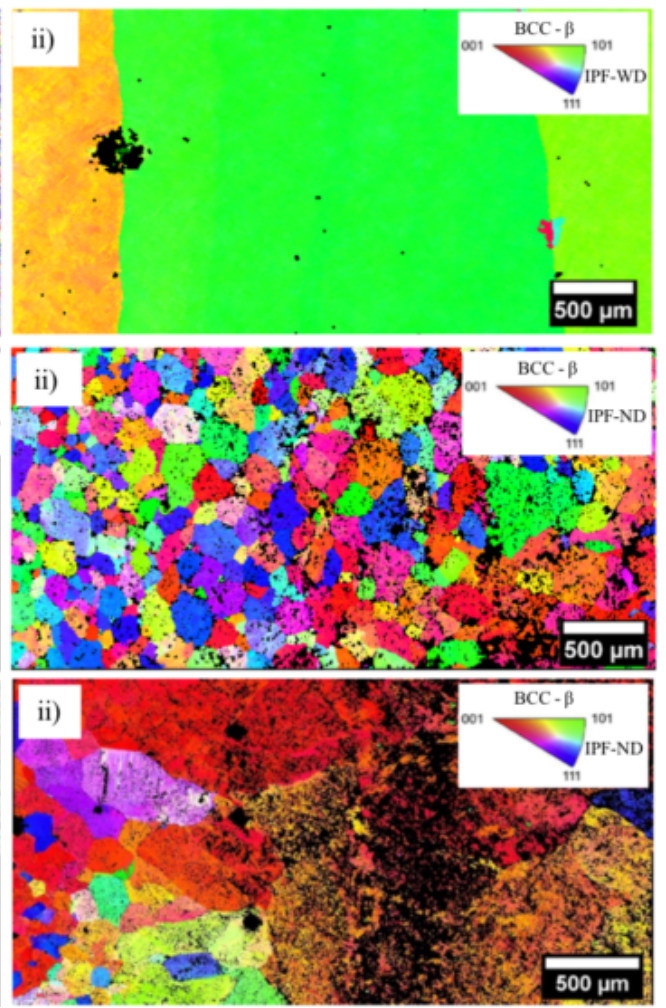

Figure 3- IPF-ND maps for the WAAM samples in (a) conventional unrolled, (b) rolled and (c) abnormal rolled conditions showing the measured $\alpha$ and reconstructed $\beta$ orientations.

Strain Mapping

Tensile tests have been performed on all the WAAM samples to allow a comparison of the strain localisation behaviour in the WD and ND directions. Due to a lack of space here, only the most heterogeneous conditions are shown. As the standard wall was built with a constant travel direction, the $\beta$ grains were tilted towards WD, by $\sim 10^{\circ}$. The data presented for this build was therefore obtained with the tensile samples aligned normal to the growth direction of the columnar $\beta$ grains with the HAZ bands oriented at about $10^{\circ}$ to the tensile axis. For the rolled samples, because there was no preferred $\beta$ grain orientation and a near-random texture, they were tested in ND, so that their HAZ bands were normal to the tensile axis (see optical images in Fig. 4).

The yield and maximum tensile strengths (Table 2) obtained are in agreement with previous work, which showed an improvement in both properties after $\beta$ grain refinement [24]. Effective shear strain $\left(\gamma_{\text {eff }}\right)$ intensity maps obtained from the test samples are presented in Fig. 4. Corresponding strain profiles at progressive loading steps, averaged in the width direction are displayed in Fig. 5, using the 95th percentile of the $\gamma_{\text {eff }}$, as the maximum value if affected by noise in the DIC results. From Fig. 4 and 5 it can be seen that the unrolled and 'abnormally' rolled samples show a much more heterogeneous strain response than the inter-pass rolled sample, which had a uniformly refined $\beta$ grain structure and weaker texture [24]. In these samples there is distinct macroscale strain patterning that suggests the underlying microstructure and/or local texture are affecting the strain heterogeneity, although there is no obvious correlation to the HAZ bands in the corresponding optical images. Strain concentration was relatively modest initially in all the samples but as Fig. 5 indicates, it developed rapidly in the unrolled and 'abnormally' rolled samples, with $\gamma_{\text {eff }}$ varying between less than 0.02 to greater than 0.10 in the 'hard' and 'soft' regions by $3 \%$ applied strain. However, in the case of the unrolled condition, the strain localisation within the high strain bands was more dispersed, which resulted in lower peak strains compared to in the 'abnormally' rolled sample (Fig. 4c) where a strain 'hot spot' developed in its centre. In contrast, the strain in the rolled sample (Fig. 4b) remained more homogeneous throughout testing, with the maximum strain concentrations being between 2-3 times that applied, compared to 5 times for the unrolled sample.

Table 2-Yield stress and tensile stress measured for the different build conditions

\begin{tabular}{lccc}
\hline & Direction & $\sigma_{\mathrm{y}}(\mathrm{MPa})$ & бmax (MPa) \\
\hline Unrolled & $\mathrm{WD}-10^{\circ}$ towards ND & 763 & 809 \\
Rolled & $\mathrm{ND}$ & 919 & 950 \\
Rolled (Abnormal) & $\mathrm{ND}$ & 864 & 889 \\
\hline
\end{tabular}




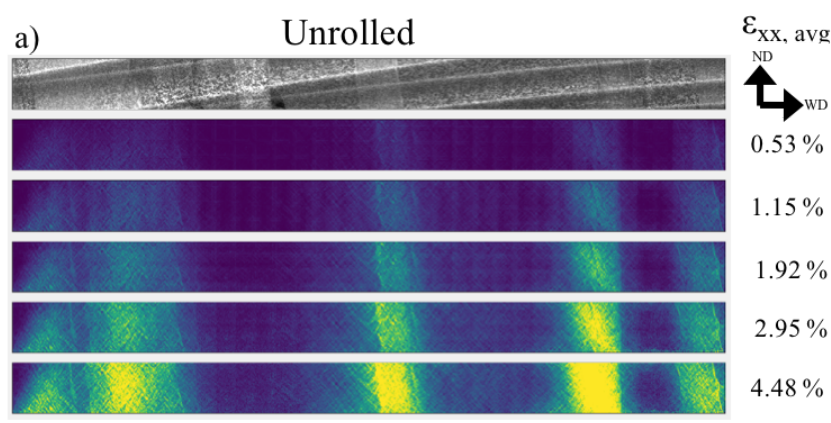

b) $\quad$ Rolled

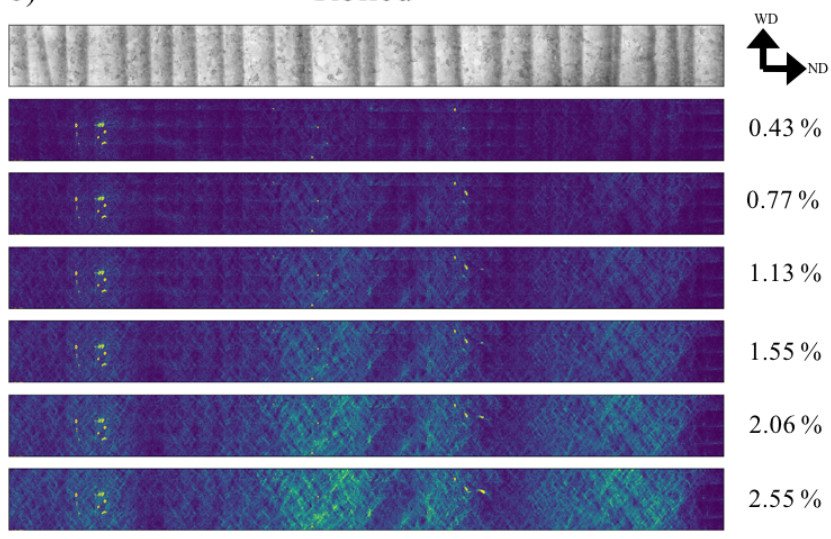

c) Rolled (Abnormal)
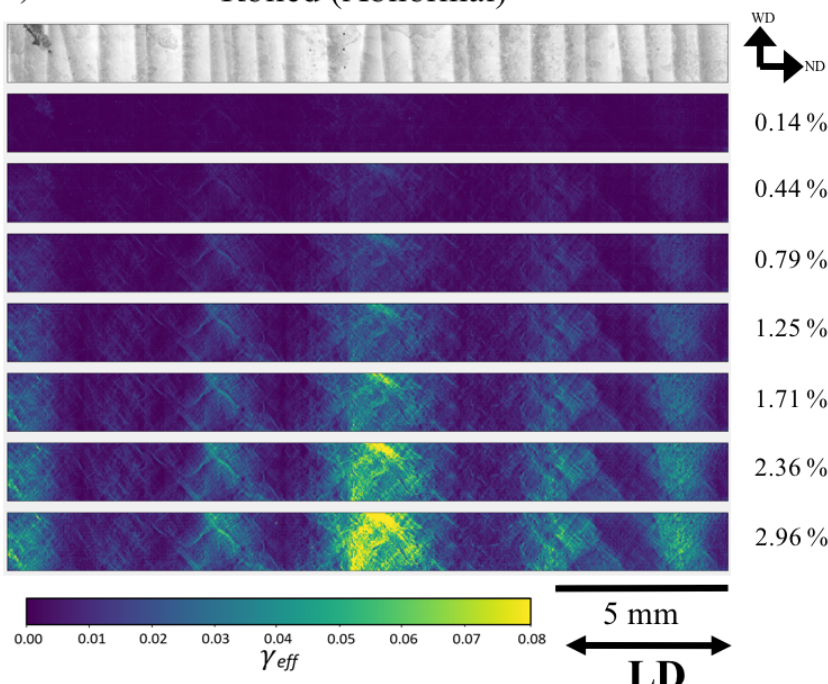

$2.96 \%$

Figure 4- Gauge length prior optical images of the tested samples with corresponding effective shear strain ( $\left.\gamma_{\mathrm{eff}}\right)$ maps, as a function of increasing applied strain, for a) conventional unrolled, (b) rolled and (c) abnormal rolled conditions. 


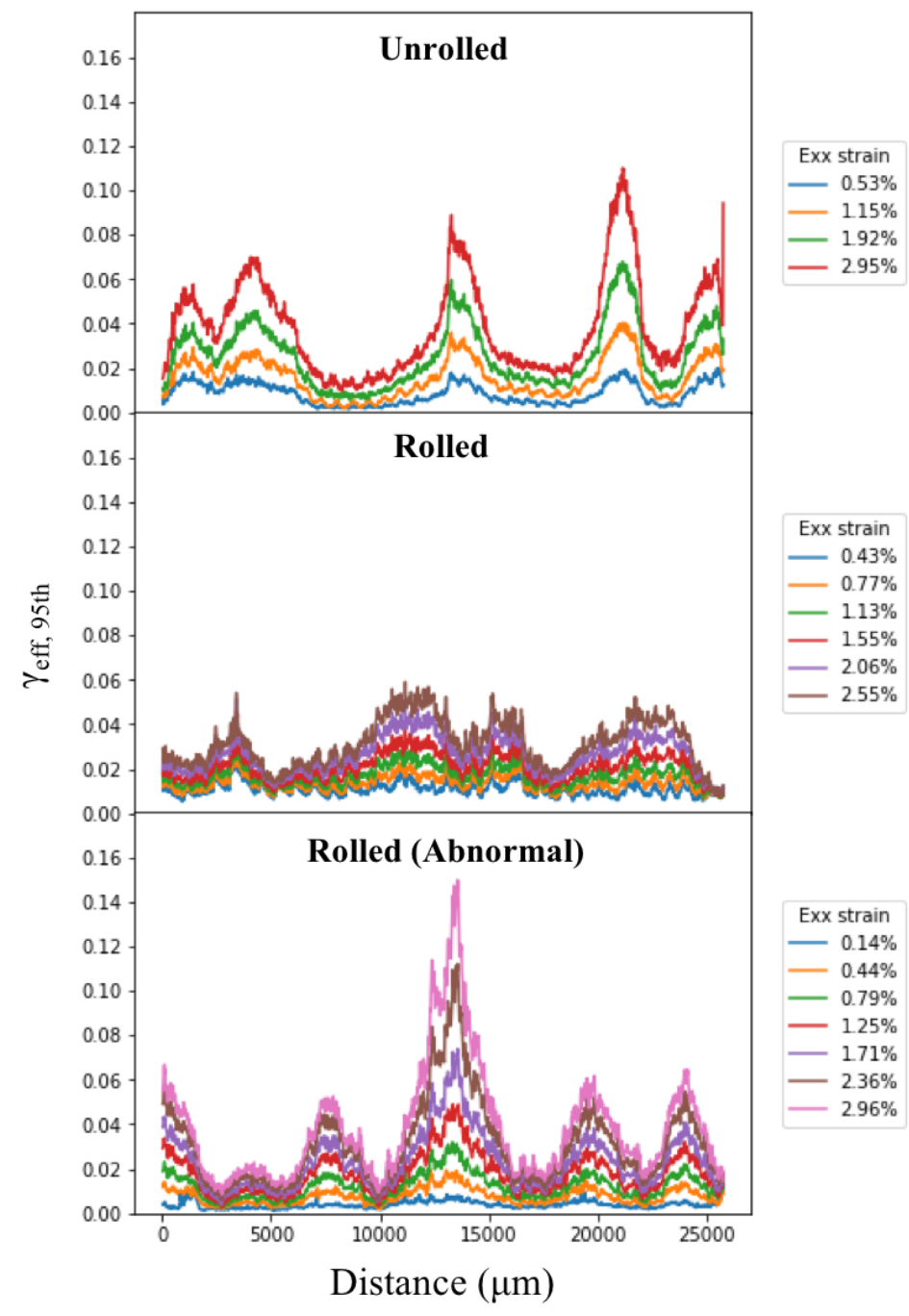

Figure 5- $95^{\text {th }}$ percentile $\gamma_{\text {eff }}$ profiles along the loading direction for each sample condition and load increment.

\section{$\underline{\text { Discussion }}$}

The unrolled and abnormally rolled WAAM samples displayed high plastic heterogeneity with maximum strain concentrations more than double that observed in the rolled wall. It is not unexpected that the small number of $\beta$ grains across the gauge length in the unrolled, and heterogeneous grain size in the abnormally rolled, samples had a detrimental impact on their strain distribution. Conversely, the refined grain size and reduction in texture produced by the rolling process led to a greatly improved and more uniform strain distribution. Fig. 6a highlights these differences by comparing the strain maps across the gauge lengths at a single loading step of $\sim 3 \%$. These observations are further supported by plots of the frequency distributions of the normalised effective shear strains (Fig. 6b) which confirms that the rolled sample exhibited significantly less strain localisation than the other two conditions, with lower maximum normalised shear strain values. There is also a distinct difference in the slope of the curve between the unrolled rolled and abnormally rolled samples, with the former having a linear tail, whereas the latter has a bimodal distribution that indicates an increase in heterogeneity. This difference is caused by the high strain localisation occurring in a single central band in the abnormally rolled specimen. The white box in Fig. 6a corresponds to Fig. 3a, which shows that a combination of large and small neighbouring grains has caused severe localisation in this region compared to in the rest of the sample.

The strain concentration in the unrolled sample tested normal to its columnar $\beta$ grain structure is clearly related to the limited $\beta$ parent grain orientations within the gauge length, but does not appear to be as localised at the GB boundaries as previously suggested [17]. To better understand the role of local texture, in Fig. 7 orientation mapping has been performed across a concentrated strain band at a higher resolution and the prismatic and basal Schmidt factor distributions for the $\alpha$ variants present compared This indicates that the deformation is reasonably uniform in the different texture regions, associated with different parent $B$ grains, but varies strongly between them - as indicated in Fig. 5. All the regions contained several variants with similar Schmidt factor distributions for prismatic slip (Fig. 7d). The main difference revealed by Fig. 7d is, however, that the soft region, R2, does not contain a variant with a low Schmidt factor for basal or prismatic slip, and has a higher density of variants favourably orientated for basal slip: i.e. in the harder regions the presence of single hard variant is primarily responsible for inhibiting plasticity.

In contrast, there was little evidence of strain concentration in the HAZ bands for any of the samples. This would be expected to be most obvious in the rolled ND sample which was not dominated by texture effects, due to its uniform fine $\beta$ grain structure. This is probably because the local yield stress variation associated with $\alpha$ coarsening within the bands is relatively modest relative to the high dependence of slip resistance on the microtexture of the HCP $\alpha$ phase. The HAZ bands are also thin and constrained by the surrounding material. 


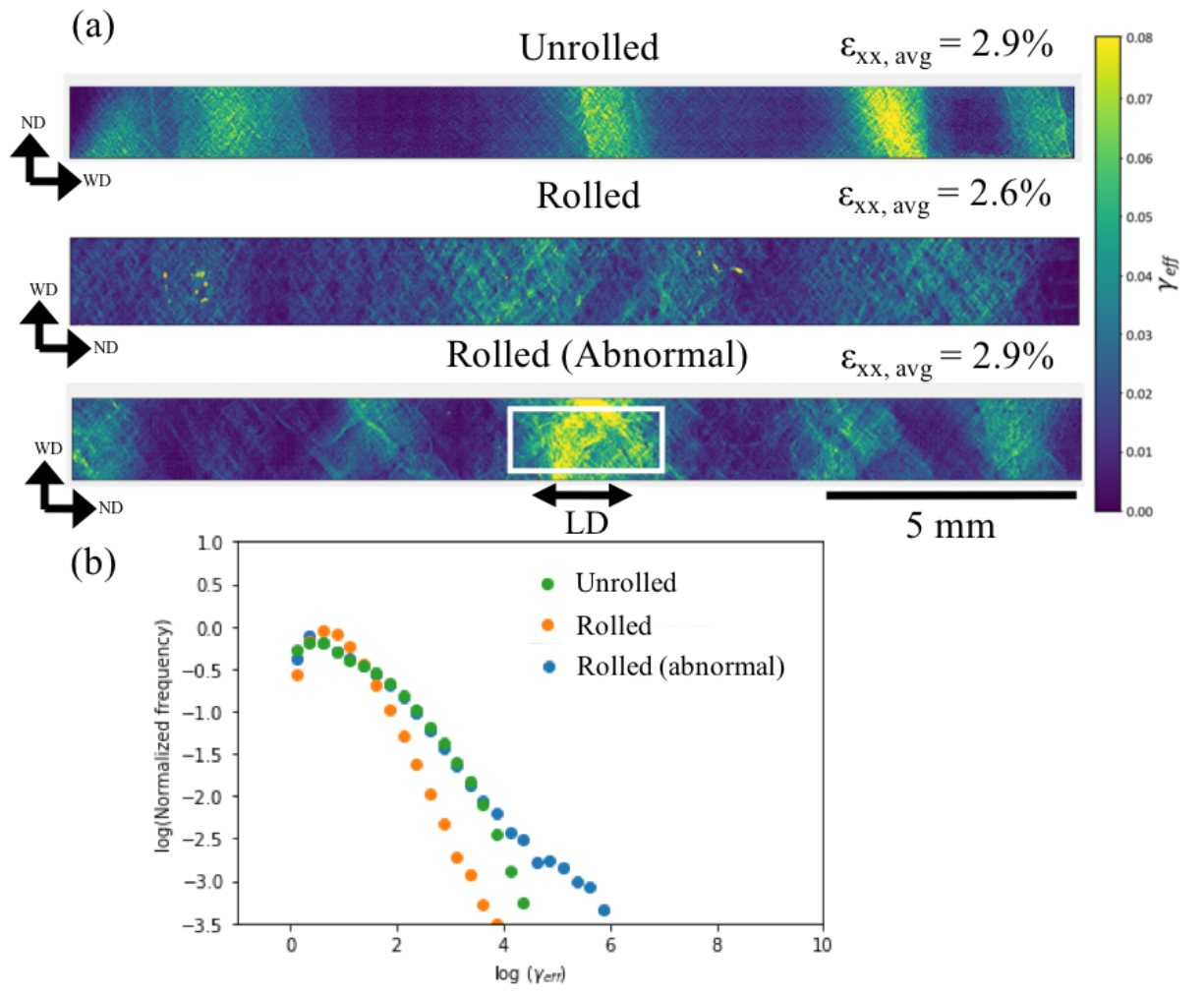

Figure 6- a) Effective shear strain maps at $\sim 3 \%$ applied strain for each condition and b) the corresponding normalised frequency distribution. The white box indicates the approximate region of the orientation map from Fig. 3 for the abnormally rolled sample.
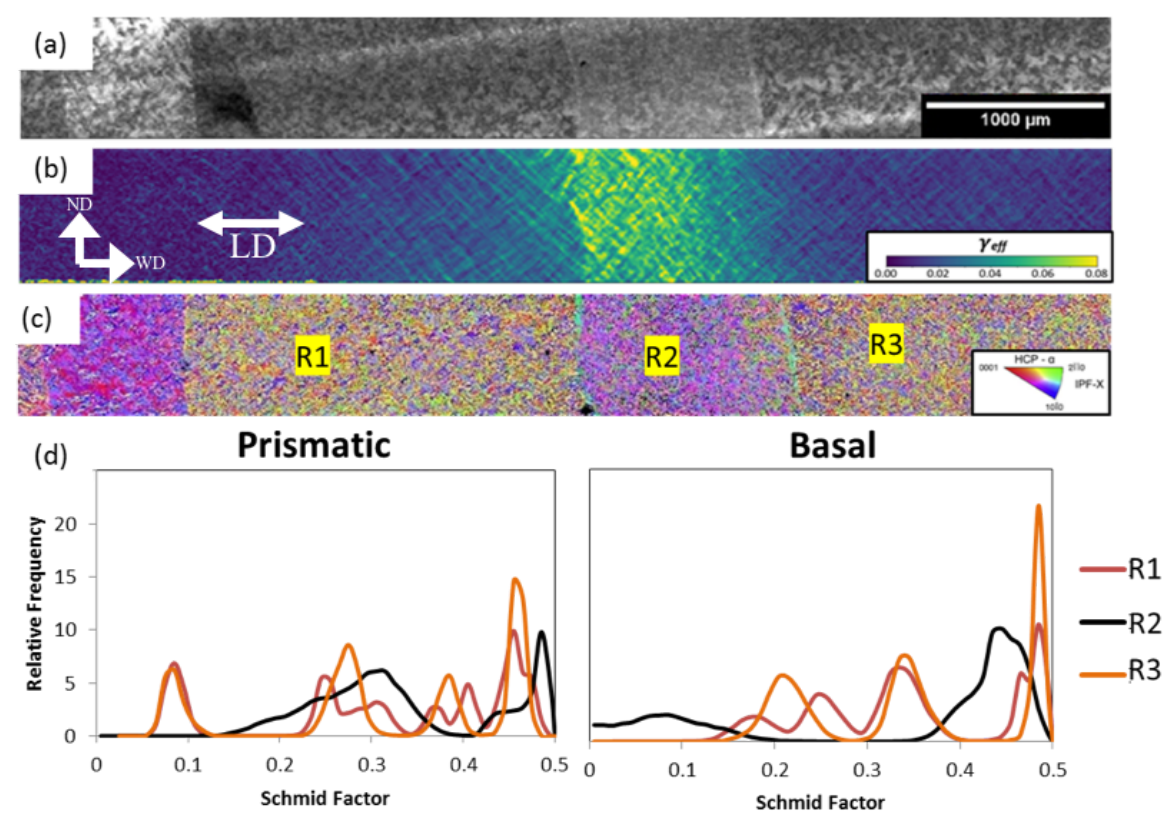

Figure 7- Comparison of the optical image, strain map and an EBSD maps across a hard (R1)-soft (R2)-hard (R3) region in the unrolled sample. (d) shows the Schmidt factor distributions for the aphase in regions identified.

\section{Conclusions}

Optical DIC strain mapping has been performed to compare the heterogeneity of deformation in Ti-6Al-4V WAAM materials produced without and with inter-pass rolling.The results have been related to the systematic microstructure and texture variation heterogeneity present in the materials. Unsurprisingly, more homogeneous strain patterning was observed in the rolled samples that had a uniformly refined $B$ grain structure.

The onset of strain localisation in the high strain regions was evident at plastic strains of less than $0.5 \%$ in both the abnormally rolled and unrolled samples and the strain patterning that developed in early strain steps remained the same throughout. The areas of low strain in the unrolled condition appeared to correlate with coarse columnar parent $\beta$ grains containing a single $\alpha$ variant with low prismatic and basal Schmidt factors, whereas little effect of HAZ banding could be detected.

The high strain localisation in the abnormally rolled condition occurred predominantly in the central high strain band, which corresponded to a region containing several large parent $\beta$ grains that were up to 8 times larger than the average grain for the sample. 
The authors are appreciative of the EPSRC's (grants LightForm - EP/R001715/1; NEWAM - EP/R027218/1), Innovate UK (Open Architecture Additive Manufacturing, OAAM) for supporting aspects of this research. P.B. Prangnell is also grateful to the Royal Academy of Engineering, UK and Airbus UK for financial support.

\section{References}

[1] Sames WJ, List FA, Pannala S, Dehoff RR, Babu SS. Int Mater Rev 2016;61:315.

[2] Liu S, Shin YC. Mater Des 2018;164:107552.

[3] Herderick E. Mater Sci Technol Conf Exhib 2011 2011;2:1413.

[4] Ho A, Zhao H, Fellowes JW, Martina F, Davis AE, Prangnell PB. Acta Mater 2019;166:306.

[5] Körner C. Int Mater Rev 2016;61:361.

[6] Brandl E, Baufeld B, Leyens C, Gault R. Phys Procedia 2010;5:595.

[7] Baufeld B, Biest O Van der, Gault R. Mater Des 2010;31:S106.

[8] Wang F, Williams S, Rush M. Int J Adv Manuf Technol 2011;57:597.

[9] Baufeld B, Brandl E, Van Der Biest O. J Mater Process Technol 2011;211:1146.

[10] Mok SH, Bi G, Folkes J, Pashby I, Segal J. Surf Coatings Technol 2008;202:4613.

[11] Brandl E, Schoberth A, Leyens C. Mater Sci Eng A 2012;532:295.

[12] Wang F, Williams S, Colegrove P, Antonysamy AA. Metall Mater Trans A Phys Metall Mater Sci 2013;44:968.

[13] Lin JJ, Lv YH, Liu YX, Xu BS, Sun Z, Li ZG, Wu YX. Mater Des 2016;102:30.

[14] Irwin J, Reutzel E (Ted), Michaleris P, Keist J, Nassar AR. J Manuf Sci Eng 2016;138:111007.

[15] Charles C, Jarvstrat N. Proc 8th Int Conf Trends Weld Res 2009:477.

[16] Martina F, Mehnen J, Williams SW, Colegrove P, Wang F. J Mater Process Technol 2012;212:1377.

[17] Åkerfeldt P, Antti M-L, Pederson R. Mater Sci Eng A 2016;674:428.

[18] Foehring D, Chew HB, Lambros J. Mater Sci Eng A 2018;724:536.

[19] Taminger KM, Hafley RA. Spec Meet Cost Eff Manuf via Net Shape Process (NATO/RTO AVT-139) 2006:16:1.

[20] Debroy T, Wei HL, Zuback JS, Mukherjee T, Elmer JW, Milewski JO, Beese AM, Wilson-heid A, De A, Zhang W. Prog Mater Sci 2018;92:112.

[21] Baufeld B, Biest O Van Der, Dillien S. Metall Mater Trans A Phys Metall Mater Sci 2010;41:1917.

[22] Kobryn PA, Semiatin SL. 2001.

[23] McAndrew AR, Alvarez Rosales M, Colegrove PA, Hönnige JR, Ho A, Fayolle R, Eyitayo K, Stan I, Sukrongpang P, Crochemore A, Pinter Z. Addit Manuf 2018;21:340.

[24] Donoghue J, Antonysamy AA, Martina F, Colegrove PA, Williams SW, Prangnell PB. Mater Charact 2016;114:103.

[25] Quinta Da Fonseca J, Mummery PM, Withers PJ. J Microsc 2005;218:9.

[26] Lunt D, da Fonseca JQQ, Rugg D, Preuss M. Mater Sci Eng A 2017;680:444.

[27] Book TA, Sangid MD. Mater Charact 2016;122:104.

[28] Davies PS. An Investigation of Microstructure and Texture Evolution in the Near- $\alpha$ Titanium Alloy Timetal 834. University of Sheffield, 2009. 